\title{
Genetic and Phenotypic Analysis of Borrelia valaisiana sp. nov. (Borrelia Genomic Groups VS116 and M19)
}

\author{
GUIQING WANG,${ }^{1}$ ALJE P. VAN DAM,${ }^{1 *}$ ANNE LE FLECHE ${ }^{2}$ DANIELE POSTIC, ${ }^{2}$ OLIVIER PETER, ${ }^{3}$ \\ GUY BARANTON, ${ }^{2}$ ROB DE BOER, ${ }^{4}$ LODEWIJK SPANJAARD,${ }^{1}$ AND JACOB DANKERT ${ }^{1}$ \\ Department of Medical Microbiology, Academic Medical Center, ${ }^{1}$ and Department of Pure and Applied \\ Ecology, ${ }^{4}$ University of Amsterdam, 1105 AZ Amsterdam, The Netherlands; Unité de Bactériologié \\ Moléculare et Médicale, Institut Pasteur, 75724 Paris Cedex 15, France ${ }^{2}$; and Clinical \\ Microbiology, Institut Central des Hopitaux Valaisans, 1950 Sion, Switzerland ${ }^{3}$
}

\begin{abstract}
To clarify the taxonomic status of two recently described Borrelia genomic groups, groups VS116 and M19, three group VS116 strains and eight group M19 strains isolated from Ixodes ricinus ticks in Switzerland, The Netherlands, and the United Kingdom were characterized. PCR-restriction fragment length polymorphism (RFLP) analysis of the 5S-23S intergenic spacer amplicon, rRNA gene restriction analysis, 16S rRNA gene sequence analysis, randomly amplified polymorphic DNA (RAPD) fingerprinting, sodium dodecyl sulfatepolyacrylamide gel electrophoresis (SDS-PAGE), and immunoblotting with monoclonal antibodies were used for genetic and phenotypic analysis. The PCR-RFLP and RAPD patterns of three group VS116 strains and eight group M19 strains were identical but differed from those of Borrelia burgdorferi sensu stricto, Borrelia garinii, Borrelia afzelii, and Borrelia japonica. DNAs from all group VS116 and M19 strains yielded three fragments $(6.9,3.2$, and $1.4 \mathrm{~kb})$ and four fragments $(2.1,1.2,0.8$, and $0.6 \mathrm{~kb})$ after digestion with $E c o R V$ and HindIII, respectively, hybridizing with an Escherichia coli $16 \mathrm{~S}+23 \mathrm{~S}$ cDNA probe. The SDS-PAGE protein profiles of group VS116 and M19 strains were heterogeneous. Phylogenetic analysis of the partial 16S rRNA gene sequences showed that group VS116 and M19 spirochetes were members of a Borrelia species distinct from previously characterized members of the genus Borrelia. Based on our present study and data from previous DNA-DNA hybridizations, a new Borrelia species, Borrelia valaisiana sp. nov., in the B. burgdorferi complex, is proposed. Strain VS116 is the type strain of this new species.
\end{abstract}

Lyme borreliosis (LB) caused by the spirochetal species Borrelia burgdorferi sensu lato is a multisystemic illness distributed worldwide (39). In North America and Eurasia, LB is the most common tick-borne disease (8). On the basis of DNA-DNA relatedness and rRNA gene restriction patterns, $B$. burgdorferi sensu lato strains have been divided into the following three species: B. burgdorferi sensu stricto, Borrelia garinii, and Borrelia afzelii $(4,9)$. B. burgdorferi sensu stricto has been found in ticks and patients infected in Europe, as well as in North America, whereas B. garinii and B. afzelii have been found only in ticks and patients infected in Eurasia $(4,41)$.

Recently, four new Borrelia species, Borrelia japonica (19), Borrelia andersonii (26), Borrelia lonestari (7), and Borrelia miyamotoi (12), have been described. B. japonica and B. andersonii were isolated from Ixodes ovatus ticks in Japan and Ixodes dentatus ticks in North America, respectively $(19,26)$. Both of these new species are considered nonpathogenic for humans. $B$. lonestari, obtained from the hard tick Amblyomma americanum and possibly the agent of an LB-like illness in the United States, and B. miyamotoi, obtained from Ixodes persulcatus in Japan, both appear to be related to relapsing fever borreliae $(7,12)$. In addition, a new Borrelia species was recovered from patients with relapsing fever and the soft tick Ornithodorus erraticus in Spain (2).

In the past, six other Borrelia genomic groups have been recognized. Five genomic groups, groups VS116, PotiB2, DN127, Hk501, and Ya501, were identified based on the MseI restriction patterns of their PCR-amplified 5S-23S rRNA in-

* Corresponding author. Mailing address: Department of Medical Microbiology, Academic Medical Center, Meibergdreef 15, $1105 \mathrm{AZ}$ Amsterdam, The Netherlands. Phone: 3120566 4863. Fax: 3120697 9271. E-mail: A. P. vanDam@amc.uva.nl. tergenic spacer amplicons (27, 31). Groups Hk501 and Ya501 are restricted to Japan $(13,27)$. Recently, these two genomic groups were reclassified as the new species Borrelia tanuki and Borrelia turdae, respectively (15). Groups VS116 and PotiB2 comprise European isolates, whereas group DN127 includes only North American isolates (31). So far, strains belonging to these genomic groups have been cultured only from ticks and small mammals. The sixth Borrelia genomic group is designated M19 and contains 12 Dutch isolates recovered from Ixodes ricinus (28). Group M19 strains, which are related to $B$. garinii, were distinguished from $B$. garinii strains based on flagellin and rRNA gene restriction patterns. More recently, it was reported that a 5S-23S rRNA intergenic spacer fragment obtained by PCR amplification from one group M19 strain reacted with a group VS116specific oligonucleotide probe (35). However, the genetic relatedness of group M19 strains with other Borrelia genomic groups is still largely unknown.

The aim of the present study was to determine the relationship between group M19 and other Borrelia species and genomic groups and to clarify the taxonomic status of genomic groups VS116 and M19. Using different genotyping and phenotyping methods, we were able to classify the eight group M19 strains used in this study into the same genomic group as group VS116 strains. Phylogenetic analysis showed that group VS116 and group M19 spirochetes represented a Borrelia species distinct from previously characterized members of the genus Borrelia. Based on our results and reports from other workers $(3,31,32,35)$, therefore, a new Borrelia species, Borrelia valaisiana sp. nov. in the B. burgdorferi complex, is designated. This species includes isolates included in formerly described genomic groups VS116 and M19 (28, 31, 32, $35)$. 
TABLE 1. B. burgdorferi sensu lato strains used in this study

\begin{tabular}{|c|c|c|c|c|}
\hline Taxon & Strain & Biological origin & Geographic location & RFLP pattern ${ }^{a}$ \\
\hline B. burgdorferi sensu stricto & $\mathrm{B} 31^{\mathrm{T}}\left(=\right.$ ATCC $\left.35210^{\mathrm{T}}\right)$ & Ixodes scapularis & United States & A \\
\hline B. garinii & $20047^{\mathrm{T}}\left(=\operatorname{CIP} 103362^{\mathrm{T}}\right)^{\prime}$ & Ixodes ricinus & France & $\mathrm{B}$ \\
\hline B. afzelii & $\mathrm{VS} 461^{\mathrm{T}}\left(=\mathrm{CIP} 103469^{\mathrm{T}}\right)$ & Ixodes ricinus & Switzerland & $\mathrm{D}$ \\
\hline B. japonica & $\mathrm{HO}^{2} 4^{\mathrm{T}}\left(=\mathrm{CJM} 8951^{\mathrm{T}}\right)$ & Ixodes ovatus & Japan & $\mathrm{E}$ \\
\hline \multirow[t]{3}{*}{ Group VS116 } & VS116 & Ixodes ricinus & Switzerland & $\mathrm{F}$ \\
\hline & UK & Ixodes ricinus & England & $\mathrm{F}$ \\
\hline & AR-2 & Ixodes ricinus & The Netherlands & $\mathrm{F}$ \\
\hline \multirow[t]{8}{*}{ Group M19 } & M7 & Ixodes ricinus & The Netherlands & $\mathrm{F}$ \\
\hline & M19 & Ixodes ricinus & The Netherlands & F \\
\hline & M38 & Ixodes ricinus & The Netherlands & $\mathrm{F}$ \\
\hline & M47 & Ixodes ricinus & The Netherlands & $\mathrm{F}$ \\
\hline & M49 & Ixodes ricinus & The Netherlands & $\mathrm{F}$ \\
\hline & M50 & Ixodes ricinus & The Netherlands & $\mathrm{F}$ \\
\hline & M52 & Ixodes ricinus & The Netherlands & $\mathrm{F}$ \\
\hline & M53 & Ixodes ricinus & The Netherlands & F \\
\hline
\end{tabular}

${ }^{a}$ RFLP patterns as described by Postic et al. (31).

\section{MATERIALS AND METHODS}

Bacterial strains and DNA extraction. The bacterial strains used in this study are listed in Table 1. Three group VS116 strains and 8 of the 12 group M19 strains known were included in this study. Four well-characterized Borrelia type strains, the type strains of $B$. burgdorferi sensu stricto, B. garinii, B. afzelii, and $B$. japonica $(4,9,19)$, were used as reference strains. Strains were grown in MKM medium (33) at $33^{\circ} \mathrm{C}$. Extraction of DNA was done as described previously (45).

PCR-restriction fragment length polymorphism (RFLP). PCR amplification of the 5S-23S intergenic spacer DNA was performed as described by Postic et al. (31); this was followed by endonuclease MseI (Boehringer, Mannheim, Germany) digestion according to the instructions of the manufacturer. The restriction fragments were subsequently electrophoresed on a $5 \%$ MetaPhor (FMC Bioproducts, Rockland, Maine) agarose gel.

Southern hybridization. Four to six micrograms of spirochete DNA was cleaved with EcoRV or HindIII (Boehringer), separated on a $0.7 \%$ agarose gel, and transferred to a nylon membrane (Zeta-probe; Bio-Rad Laboratories, Hercules, Calif.). Blots were hybridized with a digoxigenin (DIG)-labelled Escherichia coli $16 \mathrm{~S}+23 \mathrm{~S}$ cDNA probe by using a DIG labelling and detection kit (Boehringer) as described by Popovic et al. (30), except that hybridization and membrane washing were performed at 60 and $55^{\circ} \mathrm{C}$, respectively. A molecular size marker, phage lambda DNA digested with HindIII, was included in each blot and was hybridized with DIG-labelled lambda DNA.

PCR amplification of the 16S rRNA gene. Approximately $1,500 \mathrm{bp}$ of the $16 \mathrm{~S}$ rRNA gene from two group VS116 strains (VS116 and UK) was amplified by PCR by using a primer set consisting of fD3 (5'-AGAGT TTGAT CCTGG CTTAG- $3^{\prime}$; positions 8 to 27 [B. burgdorferi $\mathrm{B} 31^{\mathrm{T}}$ numbering]) and UniB $\left(5^{\prime}-\right.$ T[AC]AAGG AGGTG ATCCA GC-3'; positions 1539 to 1522 ), as described by Le Fleche et al. (23). The $5^{\prime}$ end of the $16 \mathrm{~S}$ rRNA gene from other group VS116 and M19 strains was amplified by PCR by using primers BRNA8 (5'-ACGCT GGCAG TGCGT CTTA-3') and BRNA9 (5'-CTTCG GTACT AACCT TT TAG- $3^{\prime}$ ), corresponding to nucleotides 33 to 51 and 852 to 833 of the $B$. burgdorferi sensu stricto $16 \mathrm{~S}$ ribosomal DNA (rDNA), as described previously (25). BRNA9 contains one additional nucleotide, a C (underlined), compared with the recently published sequence of the 16S rRNA gene (16).

DNA sequencing and phylogenetic analysis. The $16 \mathrm{~S}$ rRNA gene amplified with the primer set consisting of fD3 and UniB was sequenced by using a solid-phase approach with a Cy5-AutoRead sequencing kit (Pharmacia) (23). Both the 5S-23S intergenic amplicons and partial 16S rDNA fragments amplified with primers BRNA8 and BRNA9 were purified with QIAEX II (QIAGEN $\mathrm{GmbH}$, Hilden, Germany) and sequenced directly by a dideoxy chain termination method by using a dye terminator cycle sequencing kit with Taq DNA polymerase FS (Applied Biosystems, Inc., Foster, Calif.). The sequences obtained were aligned with sequences retrieved from GenBank with PC/GENE software (IntelliGenetics, Inc.). All positions with alignment gaps, as well as ambiguous positions, were excluded from the pairwise sequence comparison. Phylogenetic analysis was performed by using the MEGA program (22). A neighbor-joining tree was created based on Kimura's two-parameter distance estimation method. Bootstrap resampling was performed (100 trees).

RAPD. A randomly amplified polymorphic DNA (RAPD)-PCR analysis was performed in a $25-\mu \mathrm{l}$ reaction mixture containing $10 \mathrm{mM}$ Tris- $\mathrm{HCl}(\mathrm{pH} 8.8), 50$ $\mathrm{mM} \mathrm{KCl}, 4.0 \mathrm{mM} \mathrm{MgCl}, 0.1 \mathrm{mg}$ of bovine serum albumin per ml, each deoxynucleoside triphosphate (Pharmacia Biotech) at a concentration of $200 \mu \mathrm{M}$, $1 \mathrm{U}$ of AmpliTaq polymerase (Perkin-Elmer, Gouda, The Netherlands), $0.4 \mu \mathrm{M}$ primer 1254 (CCGCAGCCAA) or $0.4 \mu \mathrm{M}$ primer 1281 (AACGC GCAAC) (1), and $20 \mathrm{ng}$ of purified genomic DNA. The PCR was carried out with a Biometra thermocycler (Westburg B.V., Leusden, The Netherlands) by using the following steps: 3 cycles consisting of $5 \mathrm{~min}$ at $94^{\circ} \mathrm{C}, 5 \mathrm{~min}$ at $36^{\circ} \mathrm{C}$, and $5 \mathrm{~min}$ at $72^{\circ} \mathrm{C}$, followed by 30 cycles consisting of $1 \mathrm{~min}$ at $94^{\circ} \mathrm{C}, 1 \mathrm{~min}$ at $36^{\circ} \mathrm{C}$, and $2 \mathrm{~min}$ at $72^{\circ} \mathrm{C}$, and a final incubation at $72^{\circ} \mathrm{C}$ for $10 \mathrm{~min}$. The amplified DNA fragments were separated on $1 \%$ agarose gels.

SDS-PAGE and immunoblotting. Whole-cell lysates of spirochetes were analyzed by sodium dodecyl sulfate-polyacrylamide gel electrophoresis (SDSPAGE) and immunoblotting as previously described (41). OspA-specific monoclonal antibodies (MAbs) H3TS (5), LA31 (21), and LA26 (43), OspB-specific MAbs 84C (37) and I 17.3 (9), OspC-specific MAb L22 1F8 (44), and MAb D6 (29) specific for a $12-\mathrm{kDa}$ protein were used in the immunoblot analysis. MAbs H3TS, D6, and I 17.3 are specific for B. burgdorferi sensu stricto, B. garinii, and B. afzelii, respectively.

Nucleotide sequence accession numbers. The 5 S-23S spacer and $16 \mathrm{~S}$ rDNA sequences of Borrelia isolates which we determined in this study have been assigned GenBank and EMBL accession numbers. The accession numbers for the 5S-23S spacer nucleotide sequence are U78147 (strain M19), U78148 (M49), U78149 (M53), and U78150 (AR-2), and the accession numbers for the 16S rRNA gene sequence are U78151 (VS461 $\left.{ }^{\mathrm{T}}\right), \mathrm{X} 98232\left(\mathrm{VS} 116^{\mathrm{T}}\right), \mathrm{X} 98233(\mathrm{UK})$, U78153 (AR-2), U78154 (M19), 78155 (M49), and U78156 (M53). The 16S rRNA sequences of the following microorganisms (with accession numbers in parentheses) were used for phylogenetic analysis: B. burgdorferi $\mathrm{B} 31^{\mathrm{T}}$ (U03396), B. garinii $20047^{\mathrm{T}}$ (D67018), B. japonica HO14 ${ }^{\mathrm{T}}$ (L40597), B. andersonii 21038 (L46701), Borrelia sp. strain DN127 (L40596), Borrelia sp. strain Am501 (D67021), B. miyamotoi HT31 ${ }^{\mathrm{T}}$ (D45192), B. lonestari (U23211), Borretia anserina (M60970), Borrelia duttonii (U28503), and Borrelia hermsii (M60968). In addition, the 5S-23S intergenic spacer sequence of $B$. valaisiana strain VS116 ${ }^{\mathrm{T}}$ (L30134) was also used in our analysis.

\section{RESULTS}

PCR-RFLP and DNA sequence of the 5S-23S intergenic amplicon. A 246- to 255-bp fragment was generated by PCR amplification from all of the Borrelia strains used in this study.

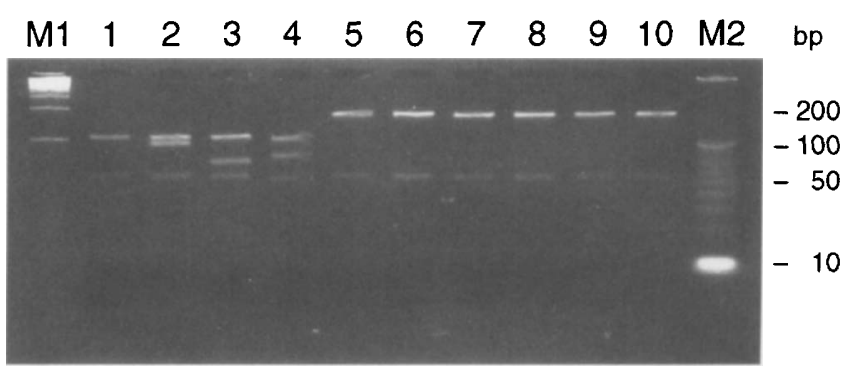

FIG. 1. MseI restriction patterns of the PCR-amplified 5S-23S intergenic spacer DNA fragment of $B$. burgdorferi sensu lato strains. Lanes 1 to 4 , reference strains $\mathrm{B} 31^{\mathrm{T}}, 20047^{\mathrm{T}}$, VS461 ${ }^{\mathrm{T}}$, and $\mathrm{HO} 14^{\mathrm{T}}$, respectively; lanes 5 to 7 , group VS116 strains VS116 ${ }^{\mathrm{T}}$, UK, and AR-2, respectively; lanes 8 to 10, group M19 strains M19, M52, and M53, respectively; lanes M1 and M2, 100- and 10-bp DNA ladders (Gibco BRL), respectively. 


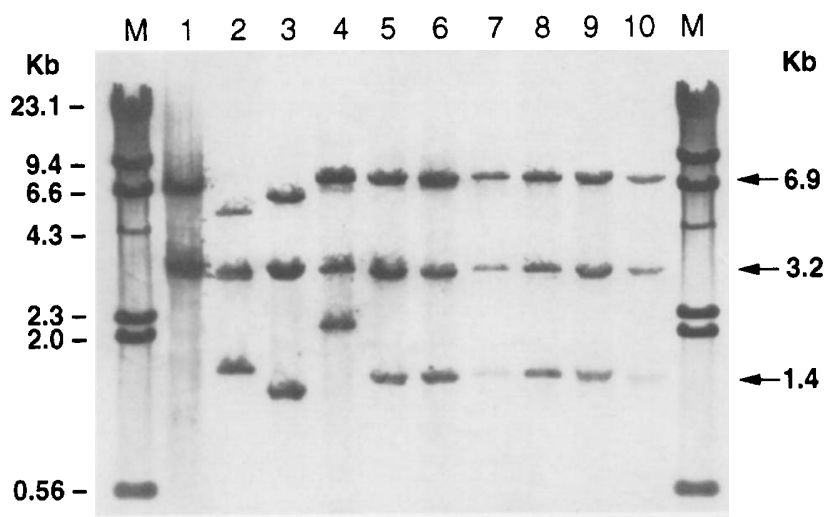

FIG. 2. rRNA gene restriction patterns of $B$. burgdorferi sensu lato strains. Genomic DNAs were digested with EcoRV, transferred to a Zeta-probe membrane, and hybridized with a digoxigenin-labelled $E$. coli $16 \mathrm{~S}+23 \mathrm{~S}$ cDNA probe. For the contents of lanes 1 through 10 see the legend to Fig. 1. The restriction fragments of Borrelia groups VS116 and M19 are indicated by the arrows on the right. Lanes M contained HindIII-digested lambda DNA.

All group VS116 and M19 strains yielded the same MseI restriction pattern with three bands having molecular sizes of 175,50 , and 23 bp (Fig. 1). This pattern, designated pattern $F$ (Table 1), differed from the $M s e I$ restriction patterns of $B$. burgdorferi sensu stricto, B. garinii, $B$. afzelii, and B. japonica. The 7-bp fragment which should be generated according to the previously published DNA sequences of two group VS116 strains (VS116 ${ }^{\mathrm{T}}$ and UK) (31) was not visualized.

In this study, we sequenced amplicons from one group VS116 strain (strain AR-2) and five group M19 strains (M7, M19, M49, M52, and M53). The amplified sequences of strains M19 and VS116 ${ }^{\mathrm{T}}$ were identical, but showed only $87.0,89.3$, 87.8 , and $86.9 \%$ identity to the sequences of strains B31, 20047, VS461, and HO14, the type strains of $B$. burgdorferi sensu stricto, $B$. garinii, B. afzelii, and B. japonica, respectively. Strains M49 and M53 showed only single nucleotide substitutions at positions 26 and 89 , respectively, when they were compared with strain VS116 ${ }^{\mathrm{T}}$. The sequences of one other group VS116 strain (AR-2) and two group M19 strains (M7 and M52) were identical to the sequence of strain UK (31) and exhibited two nucleotide differences at positions 49 and 89 compared to the strain VS116 ${ }^{\mathrm{T}}$ sequence.

rRNA gene restriction patterns. rRNA gene restriction patterns of Borrelia strains after digestion with EcoRV and hybridization with an $E$. coli $16 \mathrm{~S}+23 \mathrm{~S}$ cDNA probe on a Southern blot showed that both the three group VS116 strains and the eight group M19 strains produced three fragments with molecular sizes of $6.9,3.2$, and $1.4 \mathrm{~kb}$ (Fig. 2). Similarly, all group VS116 and M19 strains produced four fragments with molecular sizes of $2.1,1.2,0.8$, and $0.6 \mathrm{~kb}$ after cleavage with HindIII (data not shown). Based on their rRNA gene restriction patterns, the group VS116 and group M19 strains could be distinguished from $B$. burgdorferi sensu stricto, $B$. garinii, $B$. afzelii, and $B$. japonica.

16S rRNA gene analysis. Nearly complete $16 \mathrm{~S}$ rRNA gene sequences (approximately 1,500 bp) were obtained from two group VS116 strains (strains VS116 ${ }^{\mathrm{T}}$ and UK), and partial sequences (781 bp) were obtained from one group VS116 strain (AR-2) and five group M19 strains (M7, M19, M49, M52, and M53). The nearly complete sequences of the two group VS116 strains (VS116 ${ }^{\mathrm{T}}$ and UK) differed by five nucleotides and exhibited a level of similarity of $99.7 \%$. These two sequences were very similar (levels of similarity, 99.8 and

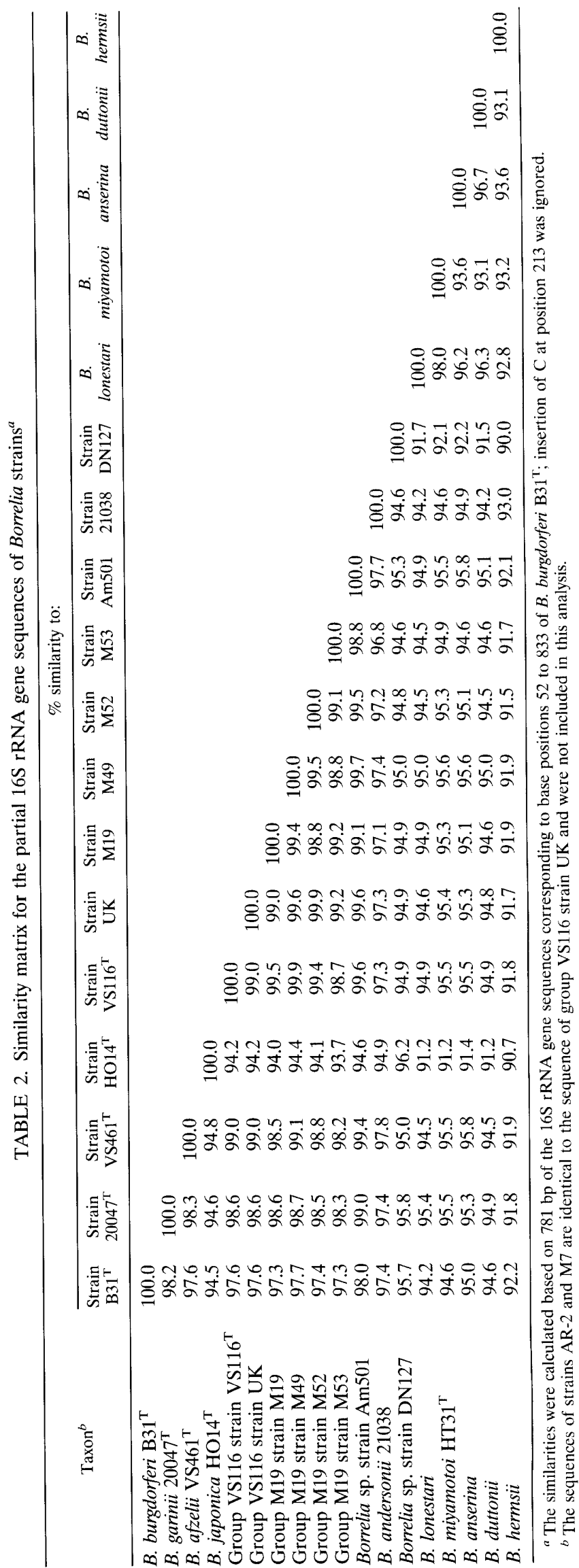




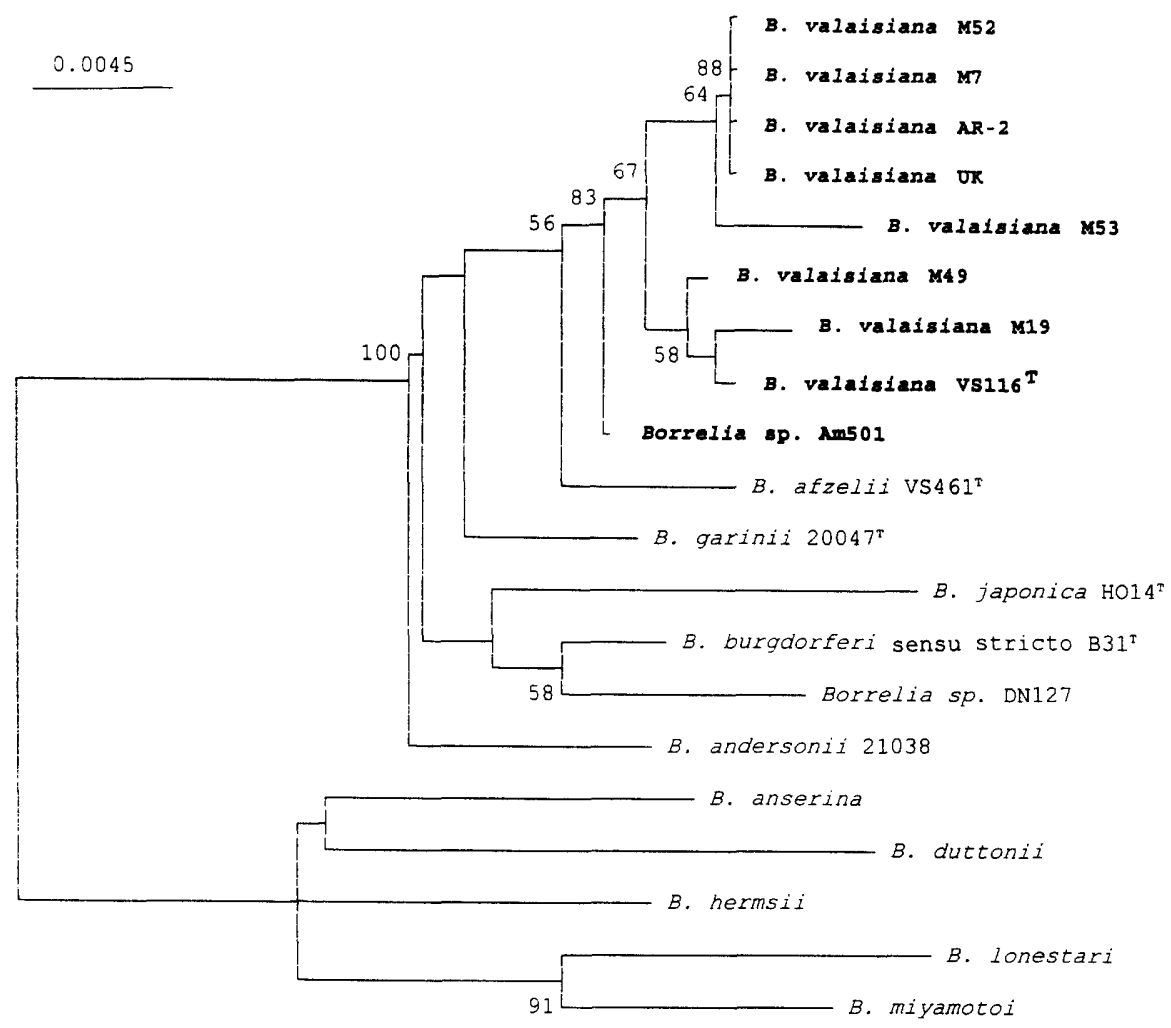

FIG. 3. Phylogenetic tree of Borrelia species and isolates. $16 \mathrm{~S}$ rRNA gene sequences, corresponding to base positions 52 to 833 of the $16 \mathrm{~S}$ rRNA of $B$. burgdorferi $\mathrm{B}^{\mathrm{T}} 1^{\mathrm{T}}$, were aligned by using the Clustal program with $\mathrm{PC} / \mathrm{Gene}$ software. The phylogenetic tree was constructed by using the MEGA program as described in the text. The numbers at the branch nodes indicate the results of the bootstrap analysis.

$99.7 \%$, respectively) to the sequence of Borrelia sp. strain Am501 isolated from an Ixodes columnae tick in Japan. The latter strain was previously found in the same cluster as strain VS1 $^{\mathrm{T}}$ in a phylogenetic tree deduced from the flagellin gene sequence (13) and clustered with strains isolated from lxodes tanuki in a tree constructed by using $16 \mathrm{~S}$ rRNA gene sequences (14). Comparison of the 781-bp sequences from all three group VS116 strains and five group M19 strains gave levels of similarity ranging from 98.8 to $100 \%$ (Table 2). Further comparison of sequences showed that group VS116 and M19 strains were more closely related to the LB-related Borrelia species than to other Borrelia species, such as B. lonestari, $B$. miyamotoi, $B$. anserina, $B$. duttonii, and $B$. hermsii (Fig. 3).

Differences in 16S rRNA coding sequences between group VS116 and M19 strains and reference strains of $B$. burgdorferi sensu stricto, $B$. garinii, and $B$. afzelii, the LB-causing species which occur in Europe, were examined in more detail. All group VS116 and M19 strains had conserved nucleotide substitutions compared to $B$. burgdorferi sensu stricto strain $\mathrm{B} 31^{\mathrm{T}}$, B. garinii $20047^{\mathrm{T}}$, and B. afzelii VS461 ${ }^{\mathrm{T}}$ at 12,9 , and 6 positions, respectively (Table 3 ). Differences in the sequences resulted in different $B f a$ I restriction patterns, which can be used to discriminate between group VS116 strains and other LB spirochetes (23).

RAPD fingerprinting. RAPD has been used for molecular analysis of various microorganisms (40). The RAPD fingerprint patterns of the three group VS116 strains and the eight group M19 strains obtained with two different arbitrary primers were similar (Fig. 4 [five group M19 strains not shown]) and

TABLE 3. Nucleotide differences in the sequences of the 16S rRNA gene from various B. burgdorferi sensu lato strains

\begin{tabular}{|c|c|c|c|c|c|c|c|c|c|c|c|c|c|c|c|c|}
\hline \multirow{2}{*}{ Taxon } & \multicolumn{16}{|c|}{ Nucleotides at the following positions ${ }^{a}$ : } \\
\hline & 77 & 85 & 86 & 126 & 143 & 244 & 271 & 273 & 376 & 473 & 613 & 627 & 676 & 708 & 836 & 1133 \\
\hline $\begin{array}{l}\text { B. burgdorferi sensu } \\
\text { stricto strain } \mathrm{B} 31^{\mathrm{T}}\end{array}$ & $\mathrm{C}$ & $\mathrm{T}$ & $\mathrm{C}$ & $\mathrm{T}$ & $\mathrm{T}$ & $\mathrm{C}$ & $\mathrm{G}$ & A & $\mathrm{G}$ & $T$ & A & $\mathrm{C}$ & $T$ & A & A & $\mathrm{G}$ \\
\hline B. garinii $20047^{\mathrm{T}}$ & $\mathrm{C}$ & $\mathrm{C}$ & $\mathrm{T}$ & $\mathrm{C}$ & $\mathrm{T}$ & $\mathrm{C}$ & $\mathrm{G}$ & G & A & $\mathrm{T}$ & $\mathrm{G}$ & A & $\mathrm{T}$ & A & A & $\mathrm{G}$ \\
\hline B. afzelii $\mathrm{VS} 461^{\mathrm{T}}$ & $\mathrm{C}$ & $\mathrm{T}$ & $\mathrm{T}$ & $\mathrm{T}$ & $\mathrm{C}$ & $\mathrm{T}$ & A & $\mathrm{G}$ & A & $\mathrm{C}$ & A & $\mathrm{G}$ & $\mathrm{C}$ & $\mathrm{G}$ & $A^{c}$ & $\mathbf{A}^{c}$ \\
\hline Groups VS116 and M19 ${ }^{b}$ & $\mathrm{~T}$ & $\mathrm{C}$ & $\mathrm{T}$ & $\mathrm{T}$ & $\mathrm{C}$ & $\mathrm{T}$ & G & $\mathrm{G}$ & A & $\mathrm{T}$ & A & A & $\mathrm{C}$ & $\mathrm{G}$ & $\mathrm{G}^{d}$ & $\mathrm{~A}^{d}$ \\
\hline
\end{tabular}

${ }^{a}$ Nucleotides are numbered in accordance with the 16S rRNA of B. burgdorferi $\mathrm{B} 31^{\mathrm{T}}(16)$.

${ }^{b}$ Includes three group VS116 strains (strains VS116 ${ }^{\mathrm{T}}$, UK, and AR-2) and five group M19 strains (strains M7, M19, M49, M52, and M53).

${ }^{c}$ Sequences at positions 836 and 1133 are based on B. afzelii DK1 (23).

${ }^{d}$ At positions 836 and 1133 only strains VS116 ${ }^{\mathrm{T}}$ and UK were sequenced. 


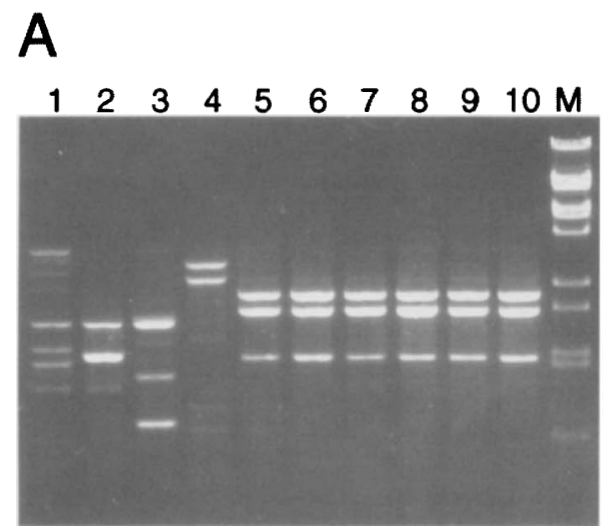

\section{B}

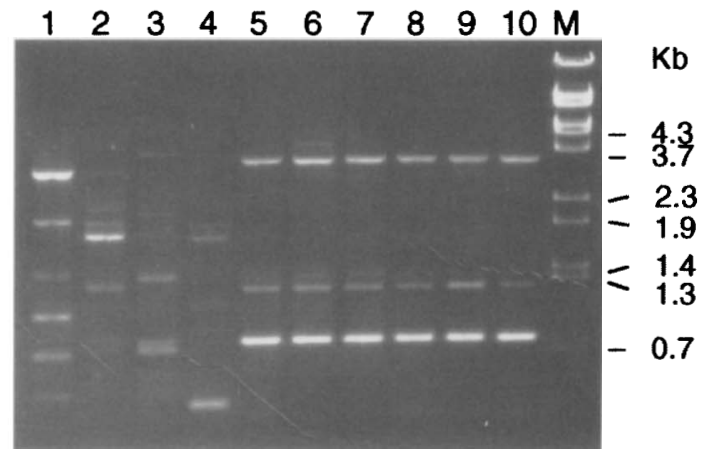

FIG. 4. RAPD fingerprinting of B. burgdorferi sensu lato strains obtained from PCR amplification with primer 1254 (A) and primer 1281 (B). For the contents of lanes 1 through 10 see the legend to Fig. 1. Lane M contained BstEII-digested lambda DNA.

clearly differed from the patterns of B. burgdorferi sensu stricto, $B$. garinii, $B$. afzelii, and $B$. japonica.

Protein profiles and reactivity with MAbs. The protein profiles of group VS116 and M19 strains differed from those of the representative strains of known LB-related Borrelia species (Fig. 5). The major outer membrane proteins in the size range from 30 to $36 \mathrm{kDa}$ were heterogeneous in the group VS116 and group M19 strains. Although a dominant protein band at 32 to $34 \mathrm{kDa}$ was present in all group VS116 and M19 strains, none of these organisms reacted with OspA-specific MAbs H3TS, LA26, and LA31 (Table 4). In contrast, 64\% (7 of 11) and 73\% ( 8 of 11) of the group VS116 and M19 strains reacted with OspB- and OspC-specific MAbs 84C and L22 1F8, respectively. The molecular masses of the OspB and OspC proteins varied among the group VS116 and M19 strains and corresponded to the molecular masses estimated from the putative OspB and OspC proteins on SDS-PAGE gels. Strains VS116 ${ }^{\mathrm{T}}$, M19, and M38 produced a putative OspB band, located just above OspA, on SDS-PAGE gels, but the proteins did not react with MAb $84 \mathrm{C}$. No reactivity of the group VS116 and M19 strains tested in this study was observed with MAbs I 17.3 and D6; these MAbs react specifically with $B$. afzelii and $B$. garinii, respectively.

\section{DISCUSSION}

Previous studies indicated that three group VS116 strains isolated from $I$. ricinus ticks in Switzerland (strains VS116 ${ }^{\mathrm{T}}$ and NE57) and in England (strain UK) were different from the well-known LB-related Borrelia species on basis of the electrophoretic mobilities of OspA (29), the RFLP patterns of the chromosomal DNA $(11,38)$, and DNA-DNA reassociation (31). Two other Borrelia isolates, AR-2 and Pn1109b, recovered from I. ricinus in The Netherlands (35) and $I$. persulcatus in Japan (32), respectively, have been classified in this group on basis of their genetic similarity to the three previously isolated group VS116 strains.

In the present study the genetic relationship between genomic groups VS116 and M19 and other LB-related Borrelia species and genomic groups was examined to determine whether considering groups VS116 and M19 a new species in the $B$. burgdorferi complex is justified. By using PCR-RFLP, RAPD fingerprinting, and rRNA gene restriction analysis, we found that the group VS116 and M19 strains were closely related to each other. Phylogenetic analysis showed that these group VS116 and M19 strains were more closely related to
LB-related Borrelia species than to other Borrelia species. Previous PCR-RFLP, DNA-DNA hybridization (31), and multilocus enzyme electrophoresis (3) studies also showed that both strain VS116 ${ }^{\mathrm{T}}$ and strain UK could not be placed into the previously described species. Therefore, they were classified in a separate genomic group, group VS116. Our results provided evidence that this genomic group should include the Borrelia group M19 strains and that group VS116 should be classified as a distinct species in the $B$. burgdorferi complex.

The geographic distribution of the new species, B. valaisiana, is not yet entirely clear. In previous studies, only five $B$. valaisiana strains were cultured from Switzerland $(11,29)$, the United Kingdom (24), The Netherlands (35), and Japan (32). Since group M19 strains accounted for $12(19 \%)$ of 63 isolates obtained from $I$. ricinus (28), we concluded that $B$. valaisiana strains are widespread among ticks in The Netherlands. This high prevalence of $B$. valaisiana infection in Dutch ticks was confirmed by a recent study conducted by Rijpkema et al. (35). It was shown by PCR amplification that the distributions of $B$.

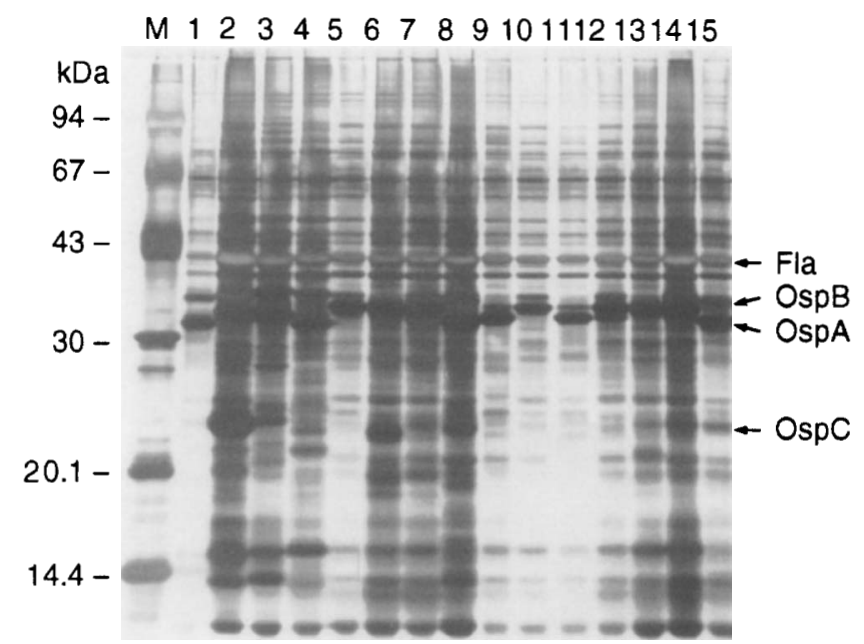

FIG. 5. Silver-stained SDS-PAGE gel of whole-cell lysates of $B$ burgdorferi sensu lato strains. Lanes 1 to 4 , strains B $31^{\mathrm{T}}, 20047^{\mathrm{T}}$, VS $461^{\mathrm{T}}$, and $\mathrm{HO} 14^{\mathrm{T}}$ of $B$. burgdorferi sensu stricto, $B$. garinii, $B$. afzelii, and $B$. japonica, respectively; lanes 5 to 7 , group VS116 strains VS116 ${ }^{\mathrm{T}}$, UK, and AR-2, respectively; lanes 8 to 15 , group M19 strains M7, M19, M38, M47, M49, M50, M52, and M53, respectively. The positions of the flagellin (Fla), OspA, OspB, and OspC proteins are indicated by arrows. The positions of molecular mass standards (Pharmacia) are shown on the left. 
TABLE 4. Major outer surface proteins of B. burgdorferi sensu lato strains and reactivities with MAbs

\begin{tabular}{|c|c|c|c|c|c|c|c|c|c|c|}
\hline \multirow{2}{*}{ Taxon } & \multirow{2}{*}{ Strain } & \multicolumn{2}{|c|}{$\begin{array}{l}\text { Molecular mass } \\
\qquad(\mathrm{kDa})^{a}\end{array}$} & \multicolumn{7}{|c|}{ Reactivities with the following MAbs: } \\
\hline & & OspA & OspB & $\begin{array}{c}\text { H3TS } \\
(\text { OspA) }\end{array}$ & $\begin{array}{c}\text { LA26 } \\
\text { (OspA) }\end{array}$ & $\begin{array}{l}\text { LA31 } \\
\text { (OspA) }\end{array}$ & $\begin{array}{c}84 \mathrm{C} \\
(\mathrm{OspB})\end{array}$ & $\begin{array}{l}\text { I } 17.3 \\
\text { (OspB) }\end{array}$ & $\begin{array}{l}\text { L22 1F8 } \\
\text { (OspC) }\end{array}$ & D6 \\
\hline B. burgdorferi sensu stricto & $\mathrm{B} 31^{\mathrm{T}}$ & 31 & 34 & + & + & + & + & - & + & - \\
\hline B. garinii & $20047^{\mathrm{T}}$ & 32 & & - & - & + & - & - & + & + \\
\hline B. afzelii & VS $461^{\mathrm{T}}$ & 32 & 35 & - & + & - & + & + & + & - \\
\hline B. japonica & $\mathrm{HO} 14^{\mathrm{T}}$ & 31 & 34.5 & - & + & + & - & - & + & - \\
\hline \multirow[t]{3}{*}{ Group VS116 } & VS116 ${ }^{\mathrm{T}}$ & 33 & $34.5^{b}$ & - & - & - & - & - & + & - \\
\hline & UK & 33 & 34.5 & - & - & $\pm^{c}$ & + & - & + & - \\
\hline & AR-2 & 33 & 34.5 & - & - & \pm & + & - & - & - \\
\hline \multirow[t]{8}{*}{ Group M19 } & M7 & 32 & 34.5 & - & - & - & + & $\mathrm{ND}^{d}$ & + & ND \\
\hline & M19 & 32.5 & $34.5^{b}$ & - & - & - & - & - & + & - \\
\hline & M38 & 33 & $35^{b}$ & - & - & - & - & ND & + & ND \\
\hline & M47 & 32.5 & 34 & - & - & - & + & ND & + & ND \\
\hline & M49 & 33.5 & 35 & - & - & - & \pm & ND & + & ND \\
\hline & M50 & 33 & & - & - & - & - & ND & - & ND \\
\hline & M52 & 33 & 35 & - & - & - & + & - & - & - \\
\hline & M53 & 32 & 34.5 & - & - & - & \pm & ND & + & ND \\
\hline
\end{tabular}

\footnotetext{
${ }^{a}$ Molecular masses were estimated by SDS-PAGE

b The molecular mass of putative OspB based on SDS-PAGE, not reactive with MAb 84C.

${ }^{c} \pm$, weak reactivity.

${ }^{d} \mathrm{ND}$, not determined
}

valaisiana, B. garinii, and B. afzelii strains in ticks in The Netherlands are similar. In addition, $B$. valaisiana DNA has also been amplified from ticks in Croatia and Ireland $(20,34)$. Therefore, it seems likely that $B$. valaisiana is present in various European countries.

The association of $B$. valaisiana with a specific tick vector appears not to be strict. Although most $B$. valaisiana strains have been isolated from $I$. ricinus in Europe, this species has been cultured once from I. persulcatus (32). It is also noteworthy that Borrelia sp. strain Am501, which based on both its flagellin (13) and its 16S rRNA gene sequence (14) belongs to $B$. valaisiana, has been cultured from $I$. columnae in Japan, showing that $B$. valaisiana can adapt to tick species other than I. ricinus. Since by xenodiagnosis several $B$. valaisiana strains have been isolated from passerine birds which were able to transmit infection to ticks, it has been suspected that passerine birds are a reservoir for this species (17).

All $B$. valaisiana strains express a dominant protein in the $32-$ to $34-\mathrm{kDa}$ range $(28,29$; this study). Although these proteins may represent OspA, they do not react with a number of monoclonal anti-OspA antibodies which have been tested (5, $21,28,43)$. Differences in the molecular weights of putative OspA proteins have been seen among $B$. valaisiana strains. However, more monoclonal anti-OspA antibodies should be tested to prove that these proteins indeed represent OspA. Most $B$. valaisiana strains included in this study expressed an OspB and an OspC, which were reactive with MAbs directed against these proteins. In addition, three strains expressed putative OspB proteins that did not react with anti-OspB MAb $84 \mathrm{C}$. Since the intensity of MAb $84 \mathrm{C}$ reactivity also varied among the MAb 84C-positive strains (data not shown), the OspBs of $B$. valaisiana strains may be heterogeneous. In an earlier publication, none of $12 \mathrm{~B}$. valaisiana strains expressed OspB, and only 1 of the strains expressed OspC (28). However, these conclusions were based only on SDS-PAGE protein profiles. We concluded that analysis of protein patterns does not constitute a reliable means for identification of $B$. valaisiana.

Whether $B$. valaisiana plays a role in human Lyme disease is still an open question. Like $B$. japonica and $B$. andersonii, which occur in Japan and North America, respectively, $B$. valaisiana strains have not yet been isolated from patients, but B. valaisiana DNA has recently been amplified from skin biopsies from two patients with erythema migrans, suggesting that this species has pathogenic potential (36). These results must be confirmed by culture of $B$. valaisiana from human tissue. If $B$. valaisiana is rather common and infectious, but exerts a low pathogenic potential, this species might well contribute to the frequent finding of asymptomatic seropositivity among residents in Switzerland (10) and The Netherlands (42), two countries where $B$. valaisiana is known to occur in ticks $(28,29)$.

Description of Borrelia valaisiana sp. nov. Borrelia valaisiana (va. lai. si. a' na. L. fem. adj. valaisiana, referring to Valais, Switzerland, where group VS116 strains were first discovered). Morphology as described previously for the genus (6). Cultural properties as described for B. burgdorferi sensu lato (18). rRNA gene restriction patterns after digestion by $E c o$ RV and HindIII contain three fragments $(6.9,3.2$, and $1.4 \mathrm{~kb})$ and four fragments $(2.1,1.2,0.8$, and $0.6 \mathrm{~kb})$, respectively. The PCRRFLP profile resulting from $M$ seI-digested 255-bp 5S-23S intergenic spacer contains four fragments $(175,50,23$, and $7 \mathrm{bp})$ (31). Reacts in Western blots with MAb H9724, but no reactivity is observed with MAbs H6831 (28), H3TS, LA26, LA31, I 17.3, and D6 (this study). Reactivity with MAbs H5332 (28), $84 \mathrm{C}$, and $\mathrm{L} 22 \mathrm{~F} 8$ is variable among strains. B. valaisiana strains have been isolated only from ticks in Eurasia. Type strain VS116, with all of the characteristics described above, was isolated from I. ricinus in Valais, Switzerland (29).

\section{ACKNOWLEDGMENTS}

We thank M. Fukunaga (Fukuyama, Japan), S. J. Cutler (London, England), and S. G. T. Rijpkema (Bilthoven, The Netherlands) for supplying Borrelia strains and A. G. Barbour, D. D. Thomas (San Antonio, Tex.), M. D. Kramer (Heidelberg, Germany), and B. Wilske (Munich, Germany) for providing MAbs. We also thank A. Oei for technical assistance, A. van der Ende and I. Schuurman for help in the development of the RAPD technique, V. V. Lukashov for assistance in the phylogenetic analysis, and W. van Est for photography. 


\section{REFERENCES}

1. Akopyanz, N., N. O. Bukanov, T. U. Westblom, S. Kresovich, and D. E. Berg. 1992. A diversity among clinical isolates of Helicobacter pylori detected by PCR-based RAPD fingerprinting. Nucleic Acids Res. 20:5137-5142.

2. Anda, P., W. Sanchez-Yebra, M. del Mar Vitutia, E. Perez Pastrana, I. Rodriguez, N. S. Miller, P. B. Backenson, and J. L. Benach. 1996. A new Borrelia species isolate from patients with relapsing fever in Spain. Lancet 348:162-165.

3. Balmelli, T., and J.-C. Piffaretti. 1996. Analysis of the genetic polymorphism of Borrelia burgdorferi sensu lato by multilocus enzyme electrophoresis. Int. J. Syst. Bacteriol. 46:167-172.

4. Baranton, G., D. Postic, I. Saint Girons, P. Boerlin, J.-C. Piffaretti, M. Assous, and P. A. D. Grimont. 1992. Delineation of Borrelia burgdorferi sensu stricto, Borrelia garinii sp. nov., and group VS461 associated with Lyme borreliosis. Int. J. Syst. Bacteriol. 42:378-383

5. Barbour, A. G., R. A. Heiland, and T. R. Howe. 1985 . Heterogeneity of major proteins in Lyme disease borreliae: a molecular analysis of North America and European isolates. J. Infect. Dis. 152:478-484.

6. Barbour, A. G., and S. F. Hayes. 1986. Biology of Borrelia species. Microbiol. Rev. 50:381-400

7. Barbour, A. G., G. O. Maupin, G. J. Teltow, C. J. Carter, and J. Piesman. 1996. Identification of an uncultivable Borrelia species in the hard tick Amblyomma americanum: possible agent of a Lyme disease-like illness. J. Infect. Dis. 173:403-409.

8. Bennett, B. E. 1995. Tick and Lyme disease. Adv. Parasitol. 36:344-405.

9. Canica, M. M., F. Nato, L. du Merle, J. C. Mazie, G. Baranton, and D. Postic. 1993. Monoclonal antibodies for identification of Borrelia afzelii sp. nov. associated with late cutaneous manifestation of lyme borreliosis. Scand. J. Infect. Dis. 25:441-448.

10. Fahrer, H., S. M. van der Linden, M. J. Sauvain, L. Gern, E. Zhioua, and A. Aeschlimann. 1991. The prevalence and incidence of clinical and asymptomatic Lyme borreliosis in a population at risk. J. Infect. Dis. 163:305-310.

11. Filipuzzi-Jenny, E., M. Blot, N. Schmid-Berger, J. Meister-Turner, and J. Meyer. 1993. Genetic diversity among Borrelia burgdorferi isolates: more than three genospecies? Res. Microbiol. 144:295-304.

12. Fukunaga, M., Y. Takahashi, Y. Tsuruta, O. Matsushita, D. Ralph, M. McClelland, and M. Nakao. 1995. Genetic and phenotypic analysis of Borrelia miyamotoi sp. nov., isolated from the Ixodes persulcatus, the vector for Lyme disease in Japan. Int. J. Syst. Bacteriol. 45:804-810.

13. Fukunaga, M., K. Okada, M. Nakao, T. Konishi, and Y. Sato. 1996. Phylogenetic analysis of Borrelia species based on flagellin gene sequences and its application for molecular typing of Lyme disease borreliae. Int. J. Syst. Bacteriol. 46:898-905.

14. Fukunaga, M., A. Hamase, K. Okada, H. Inoue, Y. Tsuruta, K. Miyamoto, and M. Nakao. 1996. Characterization of spirochetes isolated from ticks (Ixodes tanuki, Ixodes turdus, and Lodes columnae) and comparison of the sequences with those of Borrelia burgdorferi sensu lato strains. Appl. Environ. Microbiol. 62:2338-2344

15. Fukunaga, M., A. Hamase, K. Okada, and M. Nakao. 1996. Borrelia tanuki sp. nov. and Borrelia turdae sp. nov. found from Ixodes ticks in Japan: rapid species identification by $16 \mathrm{~S}$ rRNA gene-targeted PCR analysis. Microbiol. Immunol. 40:877-881.

16. Gazumyan, A., J. J. Schwart, D. Liveris, and I. Schwartz. 1994. Sequence analysis of the ribosomal RNA operon of the Lyme disease spirochete, Borrelia burgdorferi. Gene 146:57-65.

17. Humair, P. F., D. Postic, R. Wallich, and L. Gern. An avian reservoir (Turdus merula) of the Lyme disease spirochetes. Submitted for publication.

18. Johnson, R. C., G. P. Schmid, F. W. Hyde, A. G. Steigerwalt, and D. J. Brenner. 1984. Borrelia burgdorferi sp. nov.: etiological agent of Lyme disease. Int. J. Syst. Bacteriol. 34:496-497.

19. Kawabata, H., T. Masuzawa, and Y. Yanagihara. 1993. Genomic analysis of Borrelia japonica sp. nov, isolated from Ixodes ovatus in Japan. Microbiol. Immunol. 37:843-848

20. Kirstein, F., S. Rijpkema, M. Molkenboer, and J. S. Gray. 1997. The distribution and prevalence of $B$. burgdorferi genomospecies in Ixodes ricinus ticks in Ireland. Eur. J. Epidemiol. 13:67-72.

21. Kramer, M. D., U. E. Schaible, R. Wallich, S. E. Moter, D. Petzoldt, and M. M. Simon. 1990. Characterization of Borrelia burgdorferi associated antigens by monoclonal antibodies. Immunobiology 181:357-366.

22. Kumar, S., K. Tamura, and N. Masatoshi. 1993. MEGA: molecular evolutionary genetics analysis, version 1.01 . The Pennsylvania State University, University Park.

23. Le Fleche, A., D. Postic, K. Girardet, O. Peter, and G. Baranton. 1997. Characterization of Borrelia lusitaniae sp. nov. by $16 \mathrm{~S}$ ribosomal DNA sequence analysis. Int. J. Syst. Bacteriol. 47:921-925.

24. Livesley, M. A., I. P. Thompson, P. B. Rainey, and P. A. Nuttall. 1995. Comparison of Borrelia isolated from UK foci of Lyme disease. FEMS Microbiol. Lett. 130:151-158.

25. Marconi, R. T., and C. F. Garon. 1992. Development of polymerase chain reaction sets for diagnosis of Lyme disease and for species-specific identifi- cation of Lyme disease isolates by 16S rRNA signature nucleotide analysis. J. Clin. Microbiol. 30:2830-2834.

26. Marconi, R. T., D. Liveris, and I. Schwartz. 1995. Identification of novel insertion elements, restriction fragment length polymorphism patterns, and discontinuous $23 \mathrm{~S}$ rRNA in Lyme disease spirochetes: phylogenetic analysis of rRNA genes and their intergenic spacers in Borrelia japonica sp. nov. and genomic group 21038 (Borrelia andersonii sp. nov.) isolates. J. Clin. Microbiol. 33:2427-2434

27. Masuzawa, T., T. Komikado, A. Iwaki, I. Suzuki, K. Kaneda, and Y. Yanagihara. 1996. Characterization of Borrelia sp. isolated from Ixodes tanuki, I turdus, and I. columnae in Japan by restriction fragment length polymorphism of $r f$ (5S)-rrl (23S) intergenic spacer amplicons. FEMS Microbiol. Lett. 142:77-83.

28. Nohlmans, L. M. K. E., R. de Boer, A. E. J. M. van den Bogaard, and C. P. A. van Boven. 1995. Genotypic and phenotypic analysis of Borrelia burgdorferi isolates from The Netherlands. J. Clin. Microbiol. 33:119-125.

29. Péter, O., and A. G. Bretz. 1992. Polymorphism of outer surface proteins of Borrelia burgdorferi as a tool for classification. Zentralbl. Bakteriol. Parasitenkd. Infektionskr. Hyg. Abt. 1 Orig. 277:28-33.

30. Popovic, T., C. A. Bopp, O. Olsvik, and J. A. Kiehlbauch. 1993. Ribotyping in molecular epidemiology, p. 573-583. In D. H. Persing, T. F. Smith, F. C. Tenover, and T. J. White (ed.), Diagnostic molecular microbiology: principles and applications. American Society for Microbiology, Washington, D.C.

31. Postic, D., M. V. Assous, P. A. D. Grimont, and G. Baranton. 1994. Diversity of Borrelia burgdorferi sensu lato evidenced by restriction fragment length polymorphism of $r f(5 S)-r r l(23 S)$ intergenic spacer amplicons. Int. J. Syst. Bacteriol. 44:743-752

32. Postic, D., and G. Baranton. 1994. Molecular fingerprinting and phylogeny of Borrelia burgdorferi sensu lato, p. 133-147. In Y. Yanagihara and T. Masuzawa (ed.), Proceedings of the International Symposium on Lyme Disease in Japan 1994. Kanzanji, Hamamatsu, Shizuoka, Japan.

33. Preac-Mursic, V., B. Wilske, and G. Schierz. 1986. European Borrelia burgdorferi isolated from humans and ticks: culture conditions and antibiotic susceptibility. Zentralbl. Bakteriol. Parasitenkd. Infektionskr. Hyg. Abt. 1 Orig, Reihe A 263:112-118.

34. Rijpkema, S., D. Golubic, M. Molkenboer, N. Verbeek-De Kruif, and J. Schellekens. 1996. Identification of four genomic groups of Borrelia burgdorferi sensu lato in Lxodes ricinus ticks collected in a lyme borreliosis endemic region of north Croatia. Exp. Appl. Acarol. 20:23-30.

35. Rijpkema, S. G. T., M. J. C. H. Molkenboer, L. M. Schouls, F. Jongejan, and J. F. P. Schellekens. 1995. Simultaneous detection and genotyping of three genomic groups of Borrelia burgdorferi sensu lato in Dutch Ixodes ricinus ticks by characterization of the amplified intergenic spacer region between $5 \mathrm{~S}$ and 23S rRNA genes. J. Clin. Microbiol. 33:3091-3095.

36. Rijpkema, S. G. T., D. Tazelaar, M. Molkenboer, G. Noordhoek, G. Plantinga, L. Schouls, and J. Schellekens. 1997. Detection of Borrelia afzelii, Borrelia burgdorferi sensu stricto, Borrelia garinii and group VS116 by PCR in skin biopsies of patients with erythema migrans and acrodermatitis chronica atrophicans. Clin. Microbiol. Infect. 3:109-116.

37. Shoberg, R. J., M. Jonsson, A. Sadziene, S. Bergstrom, and D. D. Thomas. 1994. Identification of a highly cross-reactive outer surface protein B epitope among diverse geographic isolates of Borrelia spp. causing Lyme disease. J. Clin. Microbiol. 32:489-500.

38. Stalhammar-Carlemalm, M., E. Jenny, L. Gern, A. Aeschlimann, and J. Meyer. 1990. Plasmid analysis and restriction fragment length polymorphism of chromosomal DNA allow a distinction between Borrelia burgdorferi strains. Zentralbl. Bakteriol. Parasitenkd. Infektionskr. Hyg. Abt. 1 Orig. 274:28-39.

39. Steere, A. C. 1989. Lyme disease. N. Engl. J. Med. 321:586-596.

40. van Belkum, A. 1994. DNA fingerprinting of medically important microorganisms by PCR. Clin. Microbiol. Rev. 7:174-184.

41. van Dam, A. P., H. Kuiper, K. Vos, A. Widjojokusumo, B. M. de Jongh, L. Spanjaard, A. C. P. Ramselaar, M. D. Kramer, and J. Dankert. 1993. Different genospecies of Borrelia burgdorferi are associated with distinct clinical manifestations of Lyme borreliosis. Clin. Infect. Dis. 17:708-717.

42. Vos, K., A. P. van Dam, H. Kuiper, H. Bruins, L. Spanjaard, and J. Dankert. 1994. Seroconversion for Lyme borreliosis among Dutch military. Scand. J. Infect. Dis. 26:427-434

43. Wilske, B., V. Preac-Mursic, U. B. Gobel, B. Graf, S. Jauris, E. Soutschek, E. Schwab, and G. Zumstein. 1993. An OspA serotyping system for Borrelia burgdorferi based on reactivity with monoclonal antibodies and OspA sequence analysis. J. Clin. Microbiol, 31:340-350.

44. Wilske, B., S. Jauris-Heipke, R. Lobentanzer, I. Pradel, V. Preac-Mursic, D. Rossler, E. Soutschek, and R. C. Johnson. 1995. Phenotypic analysis of outer surface protein $\mathrm{C}(\mathrm{OspC})$ of Borrelia burgdorferi sensu lato by monoclonal antibodies: relationship to genospecies and OspA serotype. J. Clin. Microbiol. 33:103-109.

45. Wilson, K. 1988, Preparation of genomic DNA from bacteria, p. 2.4.1-2.4.5. In F. M. Ausubel (ed.), Current protocols in molecular biology, vol. 1. John Wiley \& Sons, New York, N.Y. 